\title{
Competitive Advantages and Strategic Information Systems
}

\author{
Mahmood Hemmatfar, Ph. D. \\ Faculty Member of Islamic Azad University, Brojerd Branch, Iran \\ Mahdi Salehi, Ph. D. (Corresponding author) \\ Assistant Prof. Department of Accounting and Management \\ Ferdowsi University of Mashhad, Iran \\ Tel: 98-912-1425-323 E-mail: Mahdi_salehi54@yahoo.com
}

Marziyeh Bayat, Ph. D.

Faculty Member of Islamic Azad University, Hamedan Branch, Iran

\begin{abstract}
Information edge and $3^{\text {rd }}$ millennium predisposed so many of revolutions. Business organization with emphasize on information systems is try to gathering desirable information for decision making. Because of comprehensive change in business background and emerge of computers and internet, the business structure and needed information had change, the competitiveness as a major factor for life of organizations in information edge is preyed of information technology challenges. In this article we have reviewed in the literature of information systems and discussed the concepts of information system as a strategic tool.
\end{abstract}

Keywords: Strategic information systems, Information technology, Information sciences, Decision support systems, Competitive advantages

\section{Introduction}

The potential usefulness of different kinds of Information System (IS) for environmental management is well recognized (Díez et al, 2009). Perhaps we can say advances in information provision have led organizations to attempt to develop IS or information technology (IT) strategies which interrelate with their business strategies and which together support corporate missions (Rogerson et al, 1994). The three general types of IS that are developed and in general use are financial systems, operational systems, and strategic systems. Well-directed financial systems and operational systems may well become the strategic systems for a particular organization. Relationship between IS functions and corporate strategy was not of much interest to top management of firms in recent years and so many problems because of failure in achieving strategies and that disconnecting for organizations go to existence. Modern organizations are increasingly seen as knowledge-based enterprises in which proactive knowledge management is important for competitiveness (Holsapple et al, 2000). One of the hot research topics in new decades is research about strategic IS and its aspects and Project management IS has changed considerably over the last decade (Ahlemann, 2009). One of the major factors in competitive environment is knowledge management and companies for achieving the competitive advantages should concentrate in its IS. IS has a vital role in business operation and financial and non-financial aspect such as decision making as a big role of management. ISs were thought to be synonymous with corporate data processing and treated as some back-room operation in support of day-to-day mundane tasks (Rockart, 1979). Nevertheless, in the 80 's and 90 's, there has been a growing realization of the need to make ISs of strategic importance to an organization. Strategic SISs are systems that support or shape a business unit's competitive strategy (Callon, 1996, and Neumann, 1994). Strategic ISs are touted throughout the trade press and the academic literature as the way to achieve the greatest benefits from an investment in new IT (Bajjaly, 1998). An SIS is characterized by its ability to significantly change the manner in which business is conducted, in order to give the firm strategic advantage (Turban et al, 2006). In literature we have many definitions for strategic IS such as: "The IS to support or change enterprise's strategy" (Wiseman, 1985). But clear definition is "a system that helps companies change or otherwise alter their business strategy and/or structure." It is typically utilized to streamline and quicken the reaction time to environmental changes and aid it in achieving a competitive advantage. Key features of the Strategic ISs are the following: 
1) Decision support systems that enable to develop a strategic approach to align IS or IT with an organization's business strategies

2) Primarily Enterprise resource planning solutions that integrate/link the business processes to meet the enterprise objectives for the optimization of the enterprise resources

3) Database systems with the "data mining" capabilities to make the best use of available corporate information for marketing, production, promotion and innovation. The SIS systems also facilitate identification of the data collection strategies to help optimize database marketing opportunities.

4) The real-time ISs that intend to maintain a rapid-response and the quality indicators.

Any IS that a change the goals, processes, products, or environmental relationships to help an organization gain a competitive advantage or reduce a competitive disadvantage is a strategic IS (Turban, 2006). According to Porter (1985) a competitive strategy is a broad-based formula for how a business is going to compete, what its goals should be, and what plans and policies will be required to carry out those goals.

Turban et al (2006) believes that any organization seeks a competitive advantage in their industries in other word an advantage over competitors in some measure such as cost, quality, or speed. Competitive advantage is at the core of a firm's success or failure (Porter and Millar, 1985, and Porter, 1996); such advantage seeks to lead to control of the market and to larger-than-average profits.

Some of the more common ways of thinking about gaining competitive advantage are:

1. Deliver a product or a service at a lower cost. This does not necessarily mean the lowest cost, but simply a cost related to the quality of the product or service that will be both attractive in the marketplace and will yield sufficient return on investment.

2. Deliver a product or service that us differentiated. Differentiation means the addition of unique features to a product or service that are competitive attractive in the market.

3. Focus on a specific market segment. The idea is to identify and create market niches that have not been adequately filled. IT is frequently able to provide the capabilities of defining, expanding, and filling a particular niche or segment. The application would be quite specific to the industry.

4. Innovation. Develop products or services through the use of computers that are new and appreciably from other available offerings.

A strategic IS helps an organization gain a competitive advantage through its contribution to the strategic goals of an organization and/or its ability to significantly increase performance and productivity. Turban et al (2006) believes an SIS enables companies to gain competitive advantage and to benefit greatly at the expense of those that are subject to competitive disadvantage. They said Competitive advantage in the digital economy is even more important than in the old economy. For some businesses the impact of the digital economy is revolutionary. Frequent changes in technologies and markets and the appearance of new business models can introduce radical changes in industry structure (Deise et al., 2000) and the nature of competition can shift rapidly (Afuah and Tucci, 2003, and Choi and Whinston, 2000). At the same time, the digital economy has not changed the core business of most firms. For most businesses, Internet technologies simply offer the tools, sometimes very powerful tools, which can increase their success through their traditional sources of competitive advantage - be that low cost, excellent customer service, or superior supply chain management. Bithos (2001) believe that for the overwhelming majority of businesses, the first step to competitive advantage in the digital economy are to ask and answer the question, "Where, given my industry and position, does my competitive advantage come from?" Then the follow-up question, "How can IT, especially the Internet, help my business?" will be easier to answer.

As Figure.1 shows, there were five business pressures on the company. Rosenbluth's strategic response was (1) to eliminate the retailing activities, which were most likely to be impacted by the pressures, and (2) to change the revenue model from commission-based to fee-for-service-based. Such strategy required extensive IT support (Turban et al, 2006).

At first, strategic information systems were considered to be outwardly focused - that is, aimed at increasing direct competition in an industry and visible to all. For example, strategic systems have been used to provide new services to customers and/or suppliers, to increase customer switching costs, and to lock in suppliers, all with the specific objective of achieving better results than one's competitors. But since the late 1980s, strategic systems have also been viewed inwardly: They are focused on enhancing the competitive position of the firm by 
increasing employees' productivity, streamlining business processes, and making better decisions (Turban et al, 2006). In the next part of this article we consider the role of the IT in strategic management.

As Bhatnagar (2006) believes the advances in IT have affected the lives of most of the human beings in their day-to day lives, but the strategic IS may deliver a product or service that is at a lower cost, that is differentiated, that focuses on a particular market segment, or is innovative. With the passage of time, the technology has evolved immensely and so have the opportunities. IT is being used in the business activities for improving the efficiency and effectiveness of the people and the business on the whole. The increasing demand of IS and IT has made the management of the more and more complex and difficult. SISs are different from other comparable systems as:

- They change the way the firm competes.

- They have an external (outward looking) focus.

- They are associated with higher project risk.

- They are innovative (and not easily copied).

\section{The Role of IT in Strategic Management}

A strategic IS has been defined as "the information system to support or change enterprise's strategy". Strategic management is the technique that an organization can plans the strategy of its future operations; in the other word a SIS is a system to manage information and assist in strategic decision making. The term strategic points to the long-term nature of this mapping exercise and to the large magnitude of advantage the exercise is expected to give an organization (Turban 2006). Four critical factors in developing and strategic IS are Initiation, data collection, strategy formulation and short-term development. These factors are used to prioritize proposed ISs, so that those giving competitive advantage to the organization can be highlighted for immediate development (Karababas et al, 1994). IT contributes to strategic management in many ways (for addition information see Kemerer, 1997, and Callon, 1996). Turban et al (2006) introduce these eight factors; we show these eight in figure.2:

1. Innovative applications. IT creates innovative applications that provide direct strategic advantage to organizations. For example, Federal Express was the first company in its industry to use IT for tracking the location of every package in its system. Next, FedEx was the first company to make this database accessible to its customers over the Internet. FedEx has gone on to provide e-fulfillment solutions based on IT and is even writing software for this purpose (Bhise et al., 2000).

2. Competitive weapons. ISs themselves have long been recognized as a competitive weapon (Ives and Learmouth, 1984, and Callon, 1996). Michael Dell, founder of Dell Computer, puts it bluntly: "The Internet is like a weapon sitting on the table, ready to be picked up by either you or your competitors".

3. Changes in processes. IT supports changes in business processes that translate to strategic advantage (Davenport, 1993). For example, Berri is Australia's largest manufacturer and distributor of fruit juice products. The principal goal of its enterprise resource planning system implementation was "to turn its branch-based business into a national organization with a single set of unified business processes" in order to achieve millions of dollars in cost-savings (J.D. Edwards, 2002a). Other ways in which IT can change business processes include better control over remote stores or offices by providing speedy communication tools, streamlined product design time with computer-aided engineering tools, and better decision-making processes by providing managers with timely information reports.

4. Links with business partners. IT links a company with its business partners effectively and efficiently. For example, Rosenbluth's Global Distribution Network allows it to connect agents, customers, and travel service providers around the globe, an innovation that allowed it to broaden its marketing range (Clemons and Hann, 1999).

5. Cost reductions. IT enables companies to reduce costs. For example, a Booz- Allen \& Hamilton study found that: a traditional bank transaction costs $\$ 1.07$, whereas the same transaction over the Web costs about 1 cent; a traditional airline ticket costs $\$ 8$ to process, an e-ticket costs $\$ 1$ (ibm.com/ partnerworld/pwhome.nsf/vAssetsLookup/ad2.pdf/\$file/ad2.pdf). In the customer service area, a customer call handled by a live agent costs $\$ 33$, but an intelligent agent can handle the same request for less than \$2 (Schwartz, 2000).

6. Relationships with suppliers and customers. IT can be used to lock in suppliers and customers, or to build in switching costs (making it more difficult for suppliers or customers to switch to competitors). 
7. New products. A firm can leverage its investment in IT to create new products that are in demand in the marketplace. According to Vandenbosch and Dawar (2002, p. 38), "The redefinition of ICI's role not only generated much higher margins for the business, it also gave ICI a much more defensible competitive position".

8. Competitive intelligence. IT provides competitive (business) intelligence by collecting and analyzing information about products, markets, competitors, and environmental changes (Guimaraes and Armstrong, 1997).

Turban et al, (2006) believe in battle, information about one's competitors can mean the difference between winning and losing a battle in business many companies continuously monitor the activities of their competitors to acquire competitive intelligence. Such information-gathering drives business performance by increasing market knowledge, improving knowledge management, and raising the quality of strategic planning; Comcowich (2002) considered the following uses of competitive intelligence:

- A sporting goods company found an activist group planning a demonstration and boycott months in advance, enabling the company to implement a counter strategy.

- Within days of launch, a software firm found dissatisfaction with specific product features, enabling the technicians to write a "patch" that fixed the problem within days instead of the months normally required to obtain customer feedback and implement software fixes.

- A packaging company was able to determine the location, size, and production capacity for a new plant being built by a competitor. The otherwise well protected information was found by an automated monitoring service in building permit documents within the Web site of the town where the new plant was being built.

- A telecommunications company uncovered a competitor's legislative strategy, enabling the company to gain an upper hand in a state-by-state lobbying battle.

- The creative team embarking on development of a new video game used the Internet to identify cutting-edge product attributes that game-players prefer. The intensive research uncovered three key "gotta haves" that were not identified in focus groups and had not been included in the original design specification.

Desouza believes (2001) that, Competitive intelligence can be done with technologies such as optical character recognition, intelligent agents and especially the Internet. The Internet is a company's most important tool to support competitive intelligence (Teo, 2000, Bell and Harari, 2000, and Buchwitz, 2002).

Power and Sharda (1997) proposed a framework in which the Internet capabilities are shown to provide information for strategic decisions. According to the framework, shown in Figure.3 the external information required (upper left) and the methods of acquiring information (upper right) can be supported by Internet tools for communication, searching, browsing and information retrieval.

Power and Sharda (1997) emphasize the search capability of the various tools of the Internet. Using these tools an organization can implement specific search strategies.

Turban et al, (2006) believe that with respect to this terms, it's not enough just to gather information on a competitor. Analyzing and interpreting the information is as important as collecting it. They suggest that one can use IT tools ranging from intelligent agents to data mining. Another, more sinister, aspect of competitive intelligence is industrial espionage. Industrial espionage is considered to be unethical and usually illegal.

\section{Strategies for Competitive Advantage}

As Howard et al, (1999) believed if ISs design and strategy development are addressed simultaneously, Strategic competitive advantage can be gained (Howard et al, 1999). Porter's model identifies the forces that influence competitive advantage in the marketplace. Of greater interest to most managers is the development of a strategy aimed at establishing a profitable and sustainable position against these five forces (Turban et al, 2006). To establish such a position, a company needs to develop a strategy of performing activities differently from a competitor. Porter (1985) proposed cost leadership, differentiation, and niche strategies. Additional strategies have been proposed by other strategic-management authors (e.g., Neumann, 1994; Wiseman, 1988; Frenzel, 1996). Turban et al, (2006) sited 12 strategies for competitive advantage here and we present again turban's literature. 
1. Cost leadership strategy: Produce products and/or services at the lowest cost in the industry. A firm achieves cost leadership in its industry by thrifty buying practices, efficient business processes, forcing up the prices paid by competitors, and helping customers or suppliers reduce their costs.

2. Differentiation strategy: Offer different products, services, or product features. By offering different, "better" products companies can charge higher prices; sell more products, or both.

3. Niche strategy: Select a narrow-scope segment (niche market) and be the best in quality, speed, or cost in that market.

4. Growth strategy: Increase market share, acquire more customers, or sell more products. Such a strategy strengthens a company and increases profitability in the long run. Web-based selling can facilitate growth by creating new marketing channels, such as electronic auctions.

5. Alliance strategy: Work with business partners in partnerships, alliances, joint ventures, or virtual companies. This strategy creates synergy, allows companies to concentrate on their core business, and provides opportunities for growth.

6. Innovation strategy: Introduce new products and services, put new features in existing products and services, or develop new ways to produce them. Innovation is similar to differentiation except that the impact is much more dramatic. Differentiation "tweaks" existing products and services to offer the customer something special and different. Innovation implies something so new and different that it changes the nature of the industry.

7. Operational effectiveness strategy: Improve the manner in which internal business processes are executed so that a firm performs similar activities better than rivals (Porter, 1996). Such improvements increase employee and customer satisfaction, quality, and productivity while decreasing time to market. Improved decision making and management activities also contribute to improved efficiency.

8. Customer-orientation strategy: Concentrate on making customers happy. Strong competition and the realization that the customer is king (queen) is the basis of this strategy. Web-based systems that support customer relationship management are especially effective in this area because they can provide a personalized, one-to-one relationship with each customer.

9. Time strategy: Treat time as a resource, then manage it and use it to the firm's advantage. "Time is money," "Internet time" (i.e., three months on the Internet is like a year in real time), first-mover advantage, just-in-time delivery or manufacturing, competing in time (Keen, 1988), and other time-based competitive concepts emphasize the importance of time as an asset and a source of competitive advantage. One of the driving forces behind time as a competitive strategy is the need for firms to be immediately responsive to customers, markets, and changing market conditions. A second factor is the time-to-market race. By introducing innovative products or using IT to provide exceptional service, companies can create barriers to entry from new entrants.

10. Lock in customers or suppliers strategy: Encourage customers or suppliers to stay with you rather than going to competitors. Locking in customers has the effect of reducing their bargaining power.

11. Increase switching costs strategy: Discourage customers or suppliers from going to competitors for economic reasons.

\section{SIS, competitive advantages, value chain and internet effects}

Strategic systems are those ISs that may be used gaining competitive advantage. Michael Porter's competitive forces model is one of the most popular framework for analyzing competitiveness (Porter, 1985). Porter's theories on competitive advantage are not tied to ISs, but are used by others to involve information services technologies. Porter says that there are two central questions in competitive strategy:

1. How structurally attractive is the industry?

2. What is the firm's relative position in the industry?

Both of these questions are dynamic, and neither is sufficient alone to guide strategic choices and can be influenced by competitor behavior, and both can be shaped by a firm's actions. Porter's model give techniques for getting a handle on the possible average profitability of an industry over time. The analysis of these forces is the base for estimating a firm's relative position and competitive advantage.

Accrding to porter(1985) the principal types of competitive advantage are low cost producer, differentiation, and focus. The firm has a competitive advantage if it is able to deliver its product or service at a lower cost than its 
competitors. If the quality of its product is satisfactory, this will translate into higher margins and higher returns. Another advantage is gained if the firm is able to differentiate itself in some way. Differentiation leads to offering something that is both unique and is desired, and translates into a premium price. Again, this will lead to higher margins and superior performance.

According to Turban et al, (2006), porter's model has been used to develop strategies for companies to increase their competitive edge and it also demonstrates how IT can enhance the competitiveness of corporations. It seems that two types of competitive advantage, lower cost and differentiation, are mutually exclusive. Another point of Porter's is that competitive advantage is gained through a strategy bases on scope. It is necessary to look at the breadth of a firm's activities, and narrow the competitive scope to gain focus in either an industry segment, a geographic area, a customer type, and so on. Competitive advantage is most readily gained by defining the competitive scope in which the firm is operating, and concentrating on it.

\section{The concept of value chain}

As Recklies (2001) said, the term "Value Chain" was used by Michael Porter (1985). The value chain analysis describes the activities the organization performs and links them to the organizations competitive position. He believes:

Value chain analysis describes the activities within and around an organization, and relates them to an analysis of the competitive strength of the organization. Therefore, it evaluates which value each particular activity adds to the organizations products or services. This idea was built upon the insight that an organization is more than a random compilation of machinery, equipment, people and money. Only if these things are arranged into systems and systematic activates it will become possible to produce something for which customers are willing to pay a price. Porter argues that the ability to perform particular activities and to manage the linkages between these activities is a source of competitive advantage (Recklies, 2001).

Porter (1985) distinguishes between primary activities and support activities. Primary activities are directly concerned with the creation or delivery of a product or service. They can be grouped into five main areas: inbound logistics, operations, outbound logistics, marketing and sales, and service. Each of these primary activities is linked to support activities which help to improve their effectiveness or efficiency. There are four main areas of support activities: procurement, technology development (including R\&D), human resource management, and infrastructure (systems for planning, finance, quality, information management etc.).

The Value Chain framework of Michael Porter is a model that helps to analyze specific activities through which firms can create value and competitive advantage. The goal of Primary Value Chain activities is to create value that exceeds the cost of providing the product or service, thus generating a profit margin.

- Inbound logistics include the receiving, warehousing, and inventory control of input materials.

-Operations are the value-creating activities that transform the inputs into the final product.

-Outbound logistics are the activities required to get the finished product to the customer, including warehousing, order fulfillment, etc.

-Marketing \& Sales are those activities associated with getting buyers to purchase the product, including channel selection, advertising, pricing, etc.

-Service activities are those that maintain and enhance the product's value including customer support, repair services, etc.

Any or all of these primary activities may be vital in developing a competitive advantage. The primary value chain activities described above are facilitated by support activities. Porter identified four generic categories of support activities, the details of which are industry-specific.

-Procurement - the function of purchasing the raw materials and other inputs used in the value-creating activities.

-Technology Development - includes research and development, process automation, and other technology development used to support the value-chain activities.

-Human Resource Management - the activities associated with recruiting, development, and compensation of employees.

-Firm Infrastructure - includes activities such as finance, legal, quality management, etc. 
Support activities often are viewed as "overhead", but some firms successfully have used them to develop a competitive advantage, for example, to develop a cost advantage through innovative management of ISs (porter, 1985) IT is also pervasive throughout all parts of the value chain.

Porter's model recognizes five major forces that could endanger a company's position in a given industry. These forces are and in the figure 4 Porter's five forces model, including the major determinant of each force presented:

1. The threat of entry of new competitors

2. The bargaining power of suppliers

3. The bargaining power of customers (buyers)

4. The threat of substitute products or services

5. The rivalry among existing firms in the industry

A. Cost and Competitive Advantage: Cost leadership is one of Porter's two types of competitive advantage. The cost leader delivers a product of acceptable quality at the lowest possible cost. It attempts to open up a significant and sustainable cost gap over all other competitors. The cost advantage is achieved through superior position in relation to the key cost drivers.

Cost leadership translates into above-average profits if the cost leader can command the average prices in the industry. On the other hand, cost leaders must maintain quality that is close to, or equal to, that of the competition. Achieving cost leadership usually requires trade-offs with differentiation. The two are usually incompatible.

To sustain cost advantage, Porter gives a number of cost drivers which must be understood in detail because the sustainability of cost advantage in an activity depends on the cost drivers of that activity. Some of the cost drivers which must be analyzed, understood, and controlled are:

- Scale. The appropriate type of scale must be found. Policies must be set to reinforce economies of scale in scale-sensitive activities.

- Learning. The learning curve must be understood and managed. As the organization tries to learn from competitors, it must strive to keep its own learning proprietary.

- Capacity Utilization. Cost can be controlled by the leveling of throughput.

- Linkages. Linkages should be exploited within the value chain. Work with suppliers and channels can reduce costs.

- Interrelationships. Shared activities can reduce costs.

- Integration. The possibilities for integration or de-integration should be examined systematically.

- Timing. If the advantages of being the firs mover or a late mover are understood, they can be exploited.

- Policies. Policies that enhance the low-cost position or differentiation should be emphasized.

- Location. When viewed as a whole, the location of individual activities can be optimized.

- Institutional Factors. Institutional factors should be examined to see whether their change may be helpful.

Porter gives five steps to achieving cost leadership:

- Identify the appropriate value chain and assign costs and assets to it.

- Identify the cost drivers of each value activity and see how they interact.

- $\quad$ Determine the relative costs of competitors and the sources of cost differences.

1. Develop a strategy to lower relative cost position through controlling cost drivers or reconfiguring the value chain.

2. Test the cost reduction strategy for sustainability.

B. Differentiation Advantage. Differentiation is the second of Porter's two types of competitive advantage. In the differentiation strategy, one or more characteristics that are widely value by buyers are selected. The purpose is to achieve and sustain performance that is superior to any competitor in satisfying those buyer needs. A differentiator selectively adds costs in areas that are important to the buyer. Thus, successful differentiation leads to premium prices, and these lead to above-average profitably if there is approximate cost parity. To achieve this, efficient forms of differentiation must be picked, and costs must be reduced in areas that are irrelevant to the buyer needs. 
C. Internet and Impact on Competition: According to turban et al (2006), because the Internet has changed the nature of doing business, it has also changed the nature of competition. Porter himself argues that the Internet doesn't change the model, but that it is only another tool to be used in seeking competitive advantage.

In his words, "The Internet per se will rarely be a competitive advantage. Many of the companies that succeed will be the ones that use the Internet as a complement to traditional ways of competing, not those that set their Internet initiatives apart from their established operations" (Porter, 2001, p. 64).

Porter (2001) and Harmon et al. (2001) present some ways the Internet influences competition in the five factors:

1. The threat of new entrants.

2. The bargaining power of suppliers.

3. The bargaining power of customers (buyers).

4. The threat of substitute products or services.

5. The rivalry among existing firms in the industry.

Porter concludes that the overall impact of the Internet is to increase competition, which negatively impacts profitability. According to Porter,

"The great paradox of the Internet is that its very benefits-making information widely available; reducing the difficulty of purchasing, marketing, and distribution; allowing buyers and sellers to find and transact business with one another more easily - also make it more difficult for companies to capture those benefits as profits" (2001, p. 66).

\section{Implementing and sustaining SIS}

The major problem that companies now face is how to sustain their competitive advantage. Implementing strategic ISs may be a complex undertaking due to the magnitude and the complex nature of the systems (turban et al, 2006). Strategic ISs are designed to establish a profitable and sustainable position against the forces that determine industry competition.

A sustainable strategic advantage is a strategic advantage that can be maintained for some length of time. During the period from 1970 through the late 1990s, businesses implemented numerous successful IT-based strategic systems that lasted many years. These SISs enabled the companies that owned them to enjoy a competitive advantage for several years before competitors imitated their systems (Turban et al, 2006).

Ross et al. (1996) suggest the three IT assets - people, technology, and "shared" risk and responsibility —as a way to develop sustainable competitiveness. Porter (1996) expanded his classic competitive forces model to include strategies such as growth and internal efficiency that facilitate sustainability.

Turban et al, (2006) suggest some way for accomplish competitive sustainability with the help of IT.

1. Using inward systems that are not visible to competitors.

2. If a company uses outward systems to sustain competitive advantage, one way to protect those systems is to patent them.

3. Developing a comprehensive, innovative, and expensive system that is very difficult to duplicate.

4. Using modified approach.

\section{Conclusion}

Because information has emerged as an agent of integration and the enabler of new competitiveness for today's enterprise in the global marketplace and because strategic IS supports or shapes competitive strategies, the concepts of ISs is so important, IT can be used to support a variety of strategic objectives, including creation of innovative applications, changes in business processes, links with business partners, reduction of costs, acquiring competitive intelligence, and others. In this article we consider the opinion of some of ISs scientists and reviewed the literature of strategic ISs, competitive advantage and porter's model for competitive situations. According to above subject we can say one of the important factors in new challengeable business environment is emphasis on strategic ISs and this is no ended research topic. We believe for achieving successfulness, organizations must establish all aspects of their planning structures based on strategic planning and otherwise only word that can communicative of results is failure. 


\section{References}

Ahlemann Frederik. (2009). Towards a conceptual reference model for project management information systems. International Journal of Project Management, Vol. 27, No. 1, pp. 19-30.

Ankit Bhatnagar. (2006). Strategic Information Systems Planning: Alignment of 'IS/IT' Planning and Business Planning, Unitec New Zealand.

Bell, C. R., and O. Harari, (2000). Deep! Deep! Competing in the Age of the Road Runner. New York: Warner Books, 2000.

Bhise, H., et al. (2000). The Duel for Doorstep. McKinsey Quarterly, Vol. 27, No. 2, pp.19-25.

Buchwitz, L. (2002). Using the Internet for Competitive Intelligence, [Online] Available: members.attcanada.ca/ lillyb/CI/page1.html, 2002.

Callon, J. D., (1996). Competitive Advantage through Information Technology. New York: McGraw Hill, USA.

Chaffey, D. (2002). E-business and E-C management. England: Prentice-Hall.

Charles Wiseman. (1985). Strategy and Computers. Boston: Harvard Business School Press.

Clemons, E. K., and I. H. Hann, (1999). Rosenblatt International: Strategic Transformation. Journal of MIS, Vol. 25, No. 1, Fall, pp. 10-30.

Comcowich, W. J., (2002). Integrated Internet Monitoring Solutions for CI, SCIP Online, 1(18), scip.org/news/v1i18article1.asp. October 23, 2002.

Davenport, T. H. (1999). Process Innovation: Reengineering Work through Information Technology. Boston: Harvard Business School Press, 1993. Dell, M., Keynote Address at the Direct Connect Conference, Austin, Tx, August 25, 1999.

Desouza, K. C. (2001). Intelligent Agents for Competitive Intelligence: Survey of Application. Competitive Intelligence Review, Vol. 12, 4th quarter 2001, pp. 57-63.

Edwards J.D., (2003). Customer Profile: Berri Retrieved from jdedwards.com/content/enUS/Customer-Customers/Berri, Limited Australia. PDF on May 4, 2003.

Esther Díez and Brian S. McIntosh. (2009). A review of the factors which influence the use and usefulness of information systems. Environmental Modelling \& Software, Vol.24, No. 5, pp. 588-602.

Frenzel, C. W. (1996). Management of Information Technology, 2nd ed. Cambridge, MA: Course Technology.

Gregus, Michal and Benova, Eleonora. (2006). Strategic Information Management, Comenius University, E-Leader, Slovakia 2006.

Guimaraes, T., and C. Armstrong. (1997). Exploring the Relationships Between Competitive Intelligence, IS Support, and Business Change. Competitive Intelligence Review, Vol. 9, No. 3, pp.50-78.

Holsapple C. W., and K. D Joshi. (2000). An investigation of factors that influence the management of knowledge in organizations School of Management, Carol M. Gatton College of Business and Economics, University of Kentucky, Lexington, KY 40506-0034, USA 6 December 2000.

Ives B., and G. P. Learmouth, (1984). The Information System as a Competitive Weapon. Communications of the ACM.

Kemerer, C. (1997). Information Technology and Industrial Competitiveness: How IT Shapes Competition. Boston: Kluwer Academic.

Neumann, S. (1994). Strategic Information Systems—Competition through Information Technologies. New York: Macmillan.

Porter, M. E. (1996). What Is a Strategy? Harvard Business Review, November-December 1996, pp.45-59.

Porter, M. E. (2001). Strategy and the Internet. Harvard Business Review, Vol. 79, No. 3, pp.62-74.

Porter, M. E., and V. E. Millar (1985). How information gives you competitive advantage. Harvard Business Review, Vol. 63, No. 4, pp.149-158.

Porter, Michael. (2009). Value Chain framework of Michael Porter, [Online] Available: http://www.valuebasedmanagement.net/methods_porter_value_chain.html, last access 4/2/2009.

Power, B. S., and R. Sharda, (1997). Obtaining Business Intelligence on the Internet. Long Range Planning, Vol. 42, No. 4, pp. 142-170. 
Rockart, J.F. (1979). Chief Executives Define Their Own Information Needs. Harvard Business Review, Vol. 19, No. 3.

Ross, J. W. et al. (1996). Develop Long-Term Competitiveness through IT Assets. Sloan Management Review, Vol. 60, No. 4, pp.132-148.

Schwartz, E. (2000). Web Bots Enhance Self-Serve Experience. InfoWorld, February p. 7.

Simon Rogerson and Christine Fidler (1994). Strategic Information Systems Planning: Its Adoption and Use. Information Management \& Computer Security journal, Vol. 12 Issue 3, Summer1994, pp. 12-17.

Simon Rogerson and Christine Fidler. (1994). Strategic Information Systems Planning: Its Adoption and Use. Information Management \& Computer Security journal, Vol. 20, No.4, pp. 12-17.

Smith, Howard L \& Bullers, I Jr William. (1999). A study of strategic information systems design in home health agencies. The Journal of Computer Information Systems, Vol. 6 Issue 2, pp. 10-19.

Soo W. K., and R. Narasimhan. (2002). Information system utilization in supply chain integration efforts. International Journal of Production Research, Vol. 40, Issue 18, pp.45-85.

Sotiris Karababas \& Harold Cather. (1994). Developing Strategic Information Systems. Integrated Manufacturing Systems, pp. 4-11.

Stephen T. Bajjaly. (1998). Strategic Information Systems Planning in the Public Sector, University of South Carolina. The American Review of Public Administration, Vol. 28, No. 1, pp. 75-85.

Teo, T. S. H. (2000). Using the Internet for Competitive Intelligence in Singapore. Competitive Intelligence Review, Vol. 8 Issue 2, pp.16-23.

Vandenbosch, M., and N. Dawar. (2002). Beyond Better Products: Capturing Value in Customer Interactions. Sloan Management Review, Vol. 13, Issue. 5, pp. 35-42.

Wiseman, C. (1988). Strategic Information Systems, Irwin, Homewood, Illinois.

Zijad Pita, France Cheong \& Brian Corbitt. (2008). Approaches and Methodologies for Strategic Information Systems Planning: An Empirical Study in Australia, 19th Australasian Conference on Information Systems, 3-5 Dec 2008, Christchurch.

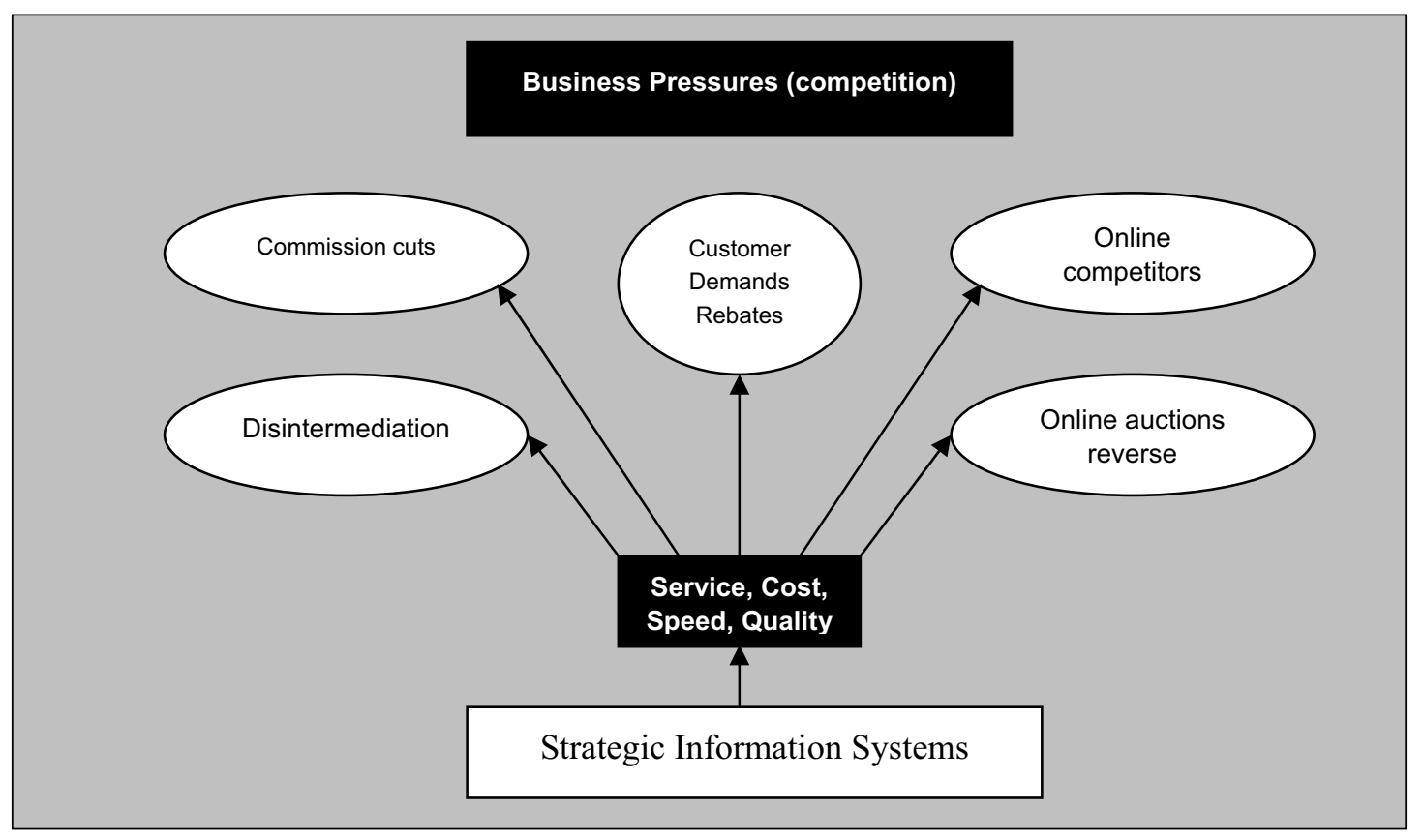

Figure 1. Strategic Information systems at Rosenbluth — defending against business pressures and competition, (resource: Turban et al, 2006, p. 93) 


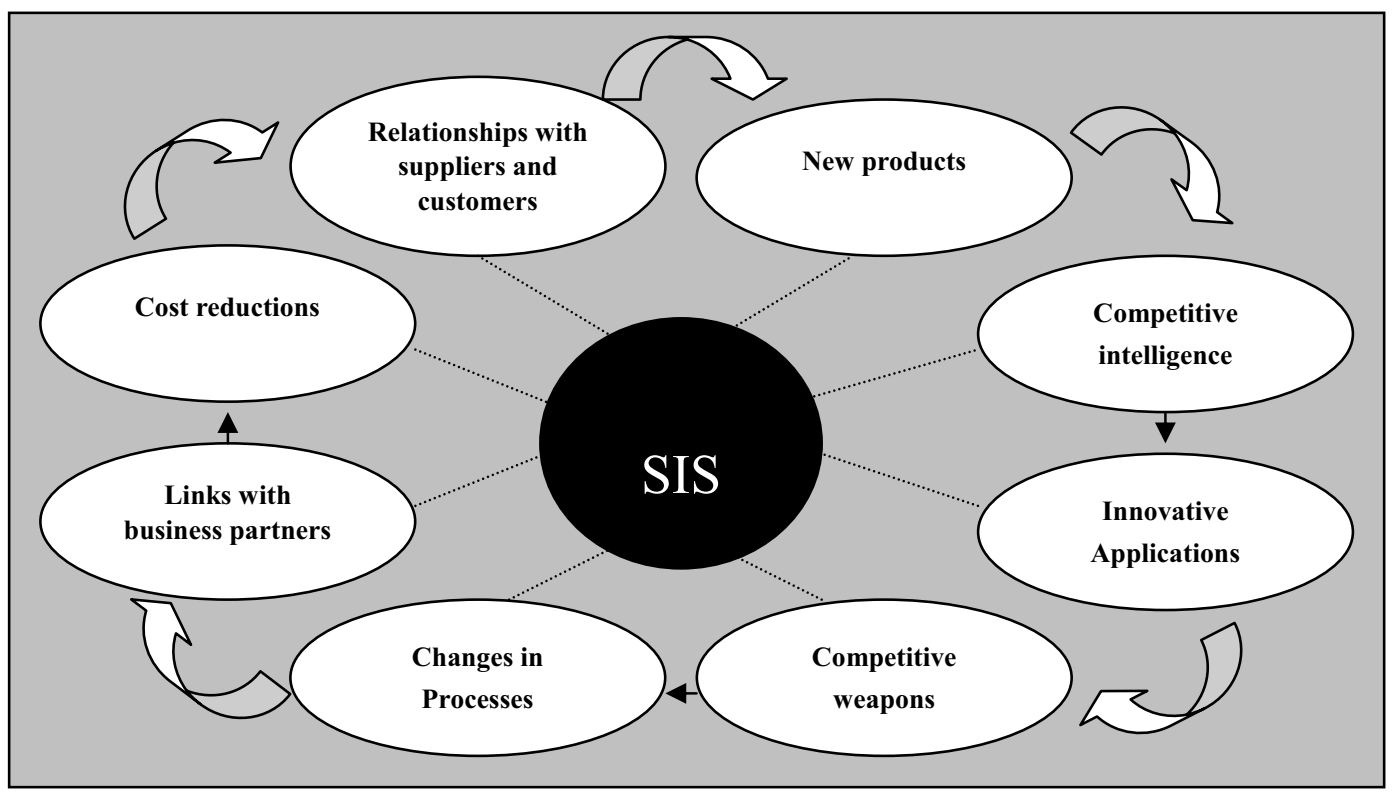

Figure 2. Strategic Information systems and strategic points (resource: Turban et al, 2006, p. 93-96)

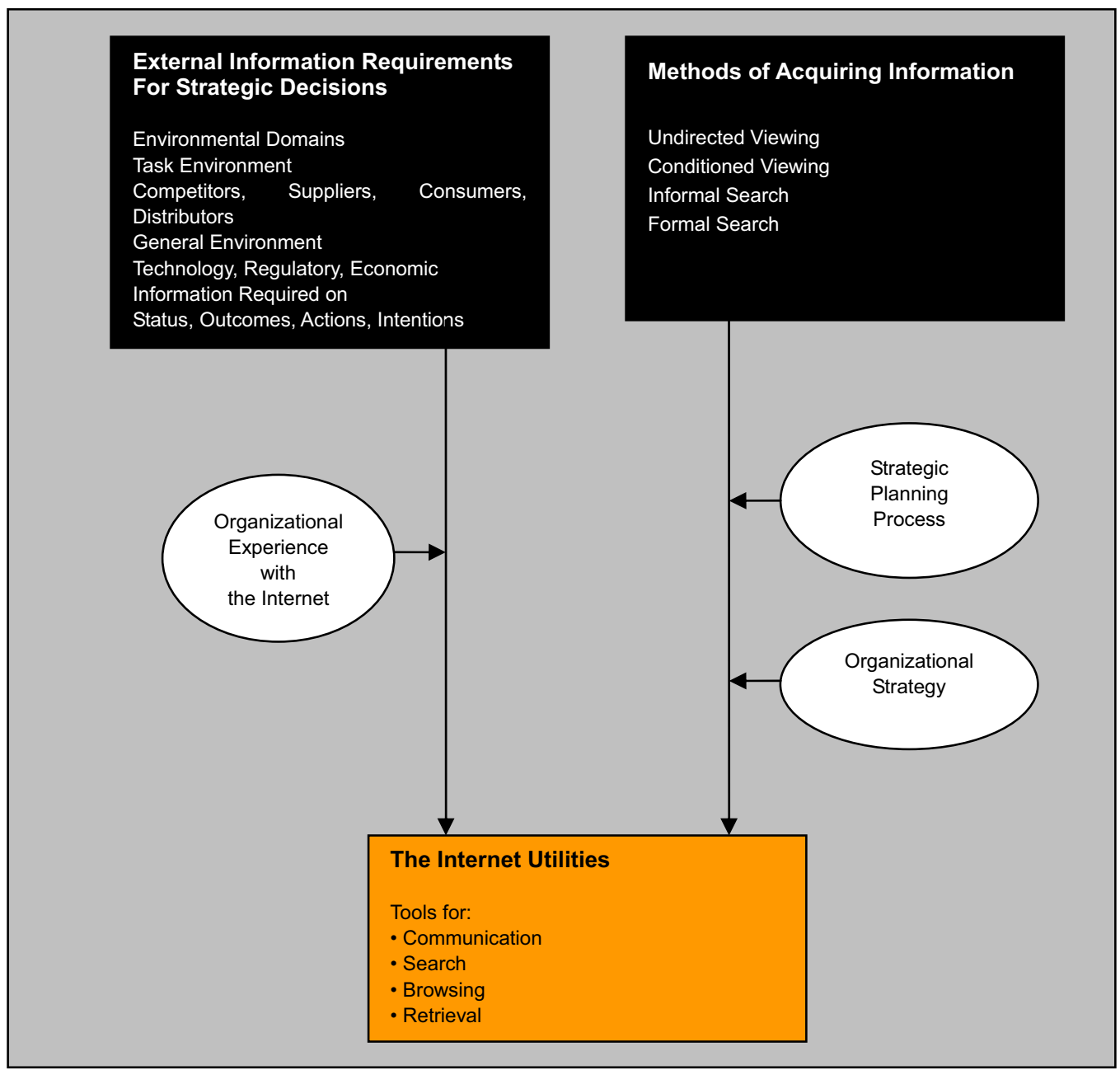

Figure 3. Strategic Information systems and strategic points (resource: Turban et al, 2003, p. 97) 


\section{Supportive Activates}

\section{Firm Infrastructure}

\section{Human Resource Management}

Technology Development

Procurement

\section{Primarilv Activates}

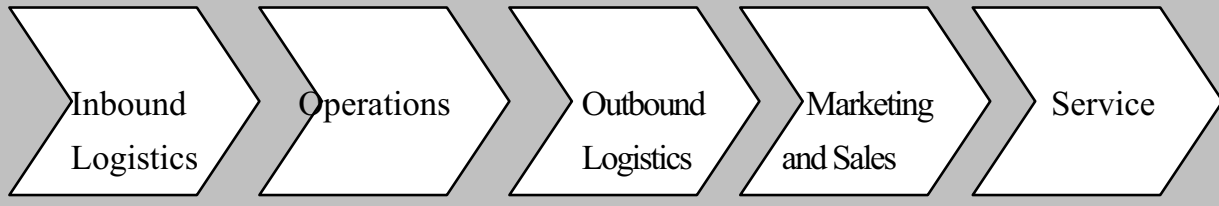

Figure 4. Michael Porter Value Chain model

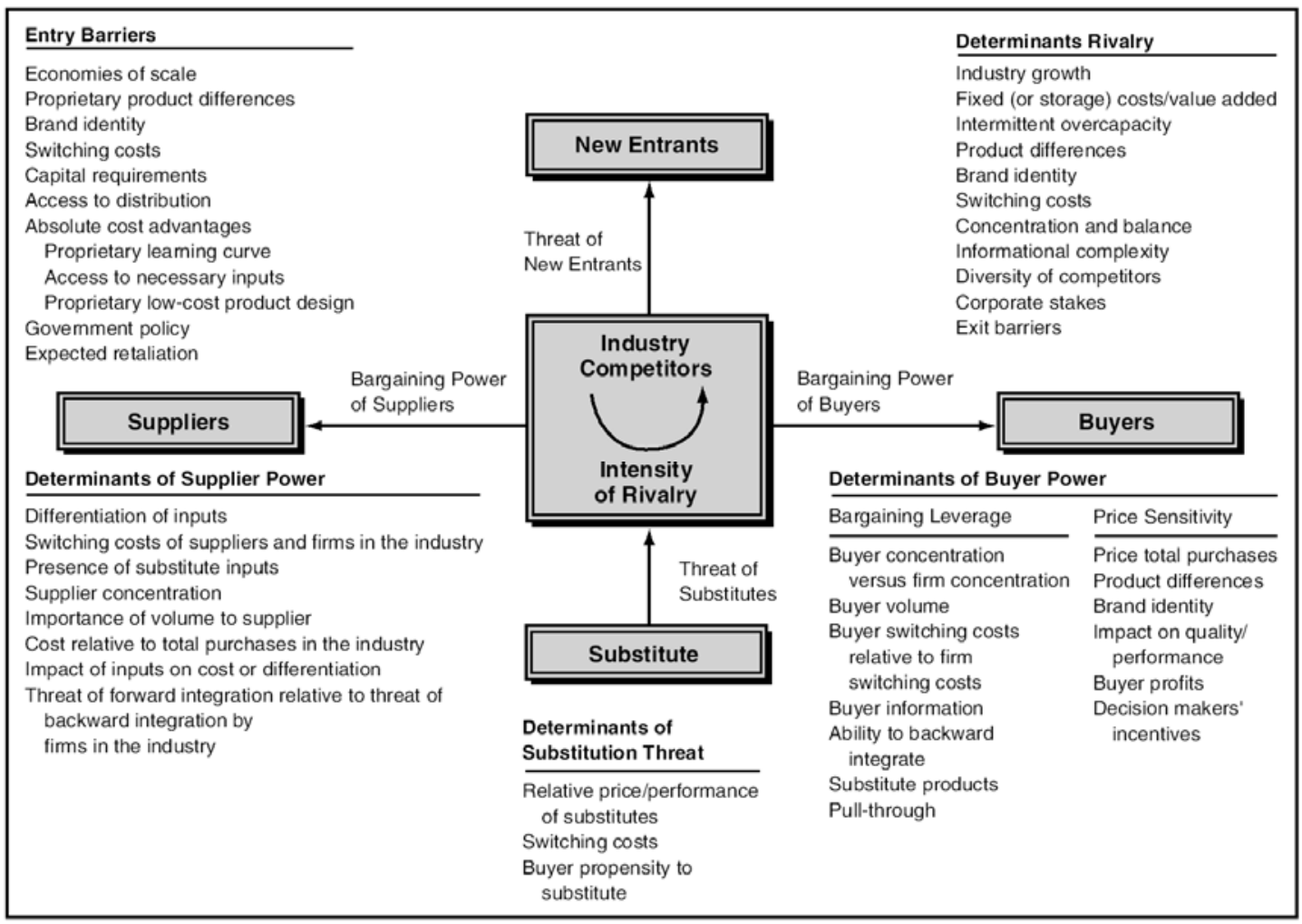

Figure 5. 